\title{
The neurotoxic effect of clindamycin - induced gut bacterial imbalance and orally administered propionic acid on DNA damage assessed by the comet assay: protective potency of carnosine and carnitine
}

\author{
Afaf El-Ansary ${ }^{1,2,4^{*}}$, Ghada H Shaker ${ }^{5}$, Amina R El-Gezeery ${ }^{1}$ and Laila Al-Ayadhi ${ }^{2,3,4}$
}

\begin{abstract}
Background: Comet assay is a quick method for assessing DNA damage in individual cells. It allows the detection of single and double DNA strand breaks, which represent the direct effect of some damaging agents. This study uses standard comet quantification models to compare the neurotoxic effect of orally administered propionic acid (PA) to that produced as a metabolite of bacterial overgrowth induced by clindamycin. Additionally, the protective effect of carnosine and carnitine as natural dietary supplements is assessed.

Methods: Single cell gel electrophoresis (comet assays) were performed on brain cortex and medulla samples after removal from nine groups of hamsters including: a control (untreated) group; PA-intoxicated group; clindamycin treated group; clindamycin-carnosine group and; clindamycin-carnitine group.

Results: There were significant double strand breaks recorded as tail length, tail moment and \% DNA damage in PA and clindamycin-treated groups for the cortex and medulla compared to the control group. Neuroprotective effects of carnosine and carnitine were observed. Receiver Operating Characteristics curve (ROC) analysis showed satisfactory values of sensitivity and specificity of the comet assay parameters.

Conclusion: Percentage DNA damage, tail length, and tail moment are adequate biomarkers of PA neurotoxicity due to oral administration or as a metabolite of induced enteric bacterial overgrowth. Establishing biomarkers of these two exposures is important for protecting children's health by documenting the role of the imbalance in gut microbiota in the etiology of autism through the gut-brain axis. These outcomes will help efforts directed at controlling the prevalence of autism, a disorder recently related to PA neurotoxicity.
\end{abstract}

Keywords: Propionic acid, Clindamycin, Tail length, Tail moment, Carnosine, Carnitine, Autism, Neurotoxicity

\section{Introduction}

The investigation of the environmental contribution towards developmental neurotoxicity is fundamental to identifying the effects of environmental contaminants on humans. Exposure to environmental chemicals may contribute to the development of neurological disorders,

\footnotetext{
* Correspondence: elansary@ksu.edu.sa

'Department of Biochemistry, College of Science, King Saud University, P.O

Box 22452, Riyadh 11495, Saudi Arabia

${ }^{2}$ Department of Physiology, Faculty of Medicine, King Saud University, P.O

Box 22452, Riyadh 11495, Saudi Arabia

Full list of author information is available at the end of the article
}

especially in children. Animal studies may help identify the etiology of neurotoxicity due to some of these environmental chemicals. Additionally, animal studies can help understanding the protective effects of some dietary supplements against neurotoxicity. Due to the high number of reports of antibiotic exposure, hospitalization, and gastrointestinal disturbances [1-3] in many children with autism spectrum disorders (ASDs), the neurobiological effects of microbiota-produced short-chain fatty acids (SCFAs), such as propionic acid (PA) has been examined [4-7]. 
Finegold et al. (2010) [8] demonstrated that there is a significantly greater diversity of bacteria in the feces of autistic subjects compared to control subjects. The increased microflora in autistic children may contain harmful genera or species contributing to the severity of autistic symptoms [8]. Two examples are Bacteroidetes and Firmicutes. The vast majority of species in the Bacteroidetes phylum produce propionic acid and lipopolysaccharides (LPS), which are well-known virulence factors.

The presence and abundance of Clostridium in the intestines of autistic children is well documented. Finegold [9] hypothesized that the relapse of some autistic children after antibiotic treatment is due to Clostridium spores. The incidence of autism is related to widespread exposure to Clostridium spores, and the increase of multiple cases of autism within a single family is also related to contact with spores [9]. Propionate has been shown to have severe neurological effects in rats $[10,11]$ and Clostridia produce propionate [12]. Studies by MacFabe et al. (2007) [10] have demonstrated that injecting propionate directly into specific regions of rat brains in vivo can cause significant behavioral problems.

MacFabe et al. (2007) [10] postulated that the overuse of antibiotics that has contributed to an increase in pathogenic bacteria of which Clostridium infections could be playing a role in the pathophysiology of autism. Additionally, clindamycin-treated hamsters are predictably susceptible to infection with pathogenic strains of Clostridium difficile and, as an animal model, they parallel most of the important aspects of human $C$. difficile associated disease (CDAD) [13]. A number of important observations were reported when a small amount of PA was infused into the brains of rodents [10]. Impact on socialization and behavior was also evaluated in a novel gut-mediated autism model [11]. Infusion with small amounts of PA resulted in social impairment, repetitive behavior and obsessive-compulsive behavior [14].

Concern has been expressed over the alarming increase in the rates of ASDs worldwide. Evaluation of the outcomes of oral administration of PA may aid in the understanding of these disorders. Hence, the present study was undertaken to investigate and evaluate the genotoxic effects associated with the oral administration of PA in comparison to overgrowth of intestinal microbiota induced in hamsters that received clindamycin. The study was extended to investigate the neuroprotective effects of carnosine and carnitine. Evaluation was done at the genotoxic levels through the use of tail length and tail moment to evaluate DNA damage as a marker of neurotoxicity.

\section{Material and methods Chemicals}

Propionic acid, carnosine and carnitine were of analytical grade from Sigma-Aldrich. Clindamycin was purchased from Pharmacia Co., Peapack, NJ, USA.

\section{Animals}

A total of 54 young male golden Syrian hamsters weighing approximately $80-100 \mathrm{~g}$ ( 8 weeks of age) were used in the present study. Animals were randomly allocated to one of 9 groups consisting of 6 animals each: a control group that received only phosphate buffered saline; an oral buffered PA-treated group that was given a neurotoxic dose of $250 \mathrm{mg} / \mathrm{kg}$ body weight/day for 3 days [15]; a clindamycintreated group that received a single dose (orogastrically) of $30 \mathrm{mg} / \mathrm{kg}$ on experiment day 0 ; a carnosine-treated group that received a dose of $10 \mathrm{mg} / \mathrm{kg}$ body weight/day orally (daily for one week); a carnitine-treated group that received $50 \mathrm{mg} / \mathrm{kg}$ body weight/day orally (daily for one week) and; four protected groups were given the same doses of carnosine or carnitine for one week followed by PA for 3 days or a single dose of clindamycin as described above. All groups were kept at a controlled temperature (21 \pm $1^{\circ} \mathrm{C}$ ) with ad-libitum access to food and water. Quantitative stool cultures were collected and tested both aerobically and anaerobically on groups of hamsters receiving clindamycin and the untreated controls. All experiments were performed in accordance with national animal care guidelines and were pre-approved by the faculty ethics committee, King Saud University.

\section{Brain tissue preparation}

At the end of the experiment, hamsters were anesthetized with carbon dioxide. The brain was removed from the skull and the cortex and medulla were extracted. Brain tissues of the nine groups were kept at $-80^{\circ} \mathrm{C}$ until use.

\section{Single cell gel electrophoresis (comet assay)}

Single cell gel electrophoresis or comet assay is a simple, sensitive and rapid method for the detection and quantification of DNA damage [16]. Slides were prepared in duplicate per group and the test was performed for at least 3 different brain (cortex and medulla) samples from each group. For the cell suspension, approximately $4 \times 10^{6}$ cells were mixed with $80 \mu \mathrm{l}$ of $0.7 \%$ low-melting agarose in phosphate-buffered saline (PBS) at $37^{\circ} \mathrm{C}$ in a microtube, and then spread over a window microscopic slide. The slides were precoated with $150 \mu \mathrm{l}$ of $0.5 \%$ normal-melting agarose in PBS, and were specially designed for this assay. The slides were immediately placed in cold lysis buffer containing $2.5 \mathrm{M}$ sodium chloride $(\mathrm{NaCl}), 100 \mathrm{mM}$ EDTA sodium salt $\mathrm{Na}_{2}$ EDTA, $10 \mathrm{mM}$ Tris ( $\mathrm{pH} 10$ ), and $1 \%$ Triton X-100, at $4^{\circ} \mathrm{C}$ for a minimum of $1 \mathrm{hr}$. After lysis, the slides were drained and placed in a horizontal gel electrophoresis tank placed in ice, and filled with fresh cold electrophoresis buffer (300 mM sodium hydroxide $(\mathrm{NaOH}), 1$ mM NaEDTA, pH 13). To allow uncoiling of DNA, the slides were kept in the high $\mathrm{pH}$ buffer for 20 minutes. Subsequently, electrophoresis was carried out for 
20 minutes at $25 \mathrm{~V}$ and $300 \mathrm{~mA}$. The slides were then drained and flooded slowly with 3 changes of neutralization buffer (0.4 M Tris, $\mathrm{pH}$ 7.5) for 5 minutes each, and then stained with $30 \mathrm{ml}$ of ethidium bromide $(20 \mathrm{mg} / \mathrm{l})$ and covered with cover slips. All those steps were performed under dimmed light to prevent additional DNA damage caused by visible light. A total of 50 randomly selected cells per slide were analyzed. Imaging was performed with a fluorescence microscope (Zeiss Axiovert L410 Inc., Jena Germany), attached to a digital camera (Olympus Inc., Tokyo, Japan), and equipped with a $549 \mathrm{~nm}$ excitation filter, $590 \mathrm{~nm}$ barrier filter, and a 100-W mercury lamp. The percentage of DNA in the comet tail ("DNA damage") was automatically calculated using a 'Toolbox' from the IN Cell Investigator analysis package (GE Healthcare Life Sciences). Tail moment was calculated as a product of tail length multiplied by tail \% damage.

\section{Measurement of colon microbiota Sample collection}

Hamsters' caecum samples were collected in sterile tubes with clindamycin- induced ileocecitis and immediately frozen at $-70^{\circ} \mathrm{C}$. The frozen tubes were sent to a microbiology laboratory for analysis. The process of bacterial cultivation involved the use of optimal artificial media and incubation conditions to isolate and identify the colon microbiota of an animal as rapidly and as accurately as possible.

\section{Isolation procedures}

Stools were usually watery, with a characteristic foul odour, mucoid and soft. Gross blood in stool did occur in some cases. Five different media were employed to isolate colon microbiota. Stool samples were diluted in glycerol transport broth [17] to yield a 1/10 dilution. Five percent sheep blood agar (BAP), MacConkey agar (MAC), Muller Hinton agar (MHA), Saboraud's Dextrose agar (SDA) (as selective medium for yeast) and modified cefoxitin cycloserine fructose agar (CCFA) (as selective medium for $C$. difficile) were used in the present study. For the quantification of C. difficile, a sample of $0.1 \mathrm{ml}$ of serial dilution was plated on CCFA and incubated at $37^{\circ} \mathrm{C}$ for at least $72 \mathrm{~h}$ in the anaerobic jar [18]. For other aerobic microorganisms, portions of $0.1 \mathrm{ml}$ of $10^{-2}, 10^{-3}$, and $10^{-4}$ dilutions were plated with a glass spreader on to BAP, MAC, MHA, and SDA. The inoculated plates were incubated at $37^{\circ} \mathrm{C}$ for 2 days in aerobic conditions.

\section{Identification criteria}

Colonies of $C$. difficile growing on CCFA, and blood agar were examined under long-wavelength ultraviolet light (Mineralite UVSL-25; Ultraviolet Products, Inc., San Gabriel, Calif.) for fluorescence. Whenever fluorescence, colonial morphology, or Gram stain morphology was characteristic of $C$. difficile, the isolate was identified by the criteria outlined in the Anaerobe Laboratory Manual [19]. Yellow fluorescence of the colonies of $C$. difficile on CCFA could be detected after $24 \mathrm{~h}$ of incubation and persisted for 5 to 6 days.

MAC or MHA and BAP media are recommended as primary plating media for most routine aerobic bacteriologic cultures. On Muller-Hinton agar plates, several bacterial species that were cultured under aerobic condition from stool samples, before and after treatment of hamsters with clindamycin, included Streptococcus, Staphylococcus aureus, Klebsiella pneumoniae, and Pseudomonas aeruginosa. There was an overgrowth of Candida albicans on SDA agar plates.

Identification of microorganisms of clinically significant streptococci ( $\beta$ hemolysis species), staphylococci, and a selected group of Gram-positive bacilli could be detected on blood agar plates after the treatment of hamsters with clindamycin. Enterobacteriaceae (lactose fermenter microorganisms) were detected on MacConkey agar media after administration of clindamycin to hamsters.

\section{Quantitative study of bacterial flora}

The quantification of culture-based methods was based on a scale of ++++ , defined as:

$0=$ no growth, $<10^{3}$ colony forming units/gram of feces

$+=$ Rare, less than $10^{3}$ colony forming units/gram of feces

$++=$ Few, $10^{3}-10^{4}$ colony forming units/gram of feces $+++=$ Moderate $10^{5}-10^{6}$ colony forming units/gram of feces

$++++=$ Heavy $>10^{6}$ colony forming units/gram of feces

(Colony-forming unit (CFU) is a measure of viable bacterial or fungal numbers. Unlike direct microscopic counts where all cells, dead and living, are counted, CFU measures viable cells) For each dilution, the number of colony forming units on the plates were counted. Typically, numbers between 30 and 300 were used to estimate the culture count.

\section{Statistical analysis}

The data were analyzed using the statistical package for social sciences (IBM Corp., New York, NY, USA). The results were expressed as mean \pm S.D. All statistical comparisons between the control and PA-treated hamster groups were performed with the one-way ANOVA test complemented with Dennett test for multiple comparisons. $P<0.05$ was statistically significant. ROC analysis was performed. Area under the curve (AUC), cutoff values, and degree of specificity and sensitivity were calculated. 
Table 1 Estimation of clindamycin-induced changes in cecal flora of hamster

\begin{tabular}{lll}
\hline $\begin{array}{l}\text { Media used and incubation } \\
\text { conditions }\end{array}$ & $\begin{array}{l}\text { Control } \\
\text { hamsters }\end{array}$ & $\begin{array}{l}\text { Clindamycin } \\
\text { recipients }\end{array}$ \\
\hline MHA/aerobic; $37^{\circ} \mathrm{C} / 24 \mathrm{~h}$ & ++ & ++++ \\
MAC/aerobic; $37^{\circ} \mathrm{C} / 24 \mathrm{~h}$ & 0 & ++ \\
$\mathrm{BAP} /$ aerobic; $37^{\circ} \mathrm{C} / 24 \mathrm{~h}$ & + & ++ \\
$\mathrm{SDA} /$ aerobic; $25^{\circ} \mathrm{C} / 48 \mathrm{~h}$ & + & ++ \\
$\mathrm{CCFA}$ anaerobic; $37^{\circ} \mathrm{C} / 72 \mathrm{~h}$ & 0 & ++ \\
\hline
\end{tabular}

MHA: Muller Hinton Agar.

MAC: MacConkey Agar.

BAP: $5 \%$ Sheep Blood Agar.

SDA: Sabouroud Dextrose agar (yeast media).

CCFA: modified Cefoxitin Cycloserine Fructose Agar.

\section{Results and discussion}

The association between bacteria and inflammation is complex as either can impact the other. Bacterial overgrowth could induce different levels of activation of the various innate sensors, which can influence the gene expression pathways, level of inflammation and the results of these changes on DNA damage and chromatin alterations. Numerous studies [20-22] have verified the association between an alteration of the dominant phyla of bacteria in the gut and systemic effects in humans and animal models. Gut microbes can impact insulin resistance, inflammation, and adiposity via interactions with epithelial and endocrine cells [20]. The intestinal epithelial cells (IECs) have a complex and mutually beneficial relationship with the gut flora. The bacteria metabolize some nutritional components in the gut, e.g. carbohydrates; in turn, the IECs metabolize the shortchain fatty acids (e.g. propionic and acetic acid) and use them as a source of energy. The microflora in the gut is essential for processing dietary polysaccharides. The data in Table 1 indicate that clindamycin was effective in inducing intestinal overgrowth of microbiota. The most striking changes in feces of clindamycin-treated hamsters, as compared with untreated controls, included, a marked increase in total Clostridia species and Klebsiella pneumoniae, with a smaller increase in Group A Streptococci. The low counts of bacteria recovered from some of the specimens were likely due to several factors including dilution effects of diarrhea and the reduction in the number of viable bacteria caused by freezing and/or prolonged storage at $-70^{\circ} \mathrm{C}$.

The induction of pathogenic bacteria in hamsters that received clindamycin could be related to the etiology of autistic biochemical characteristics previously induced in rats that received oral propionic acid, a metabolite of some pathogenic enteric bacteria [23]. It is well documented that autistic patients show bacterial overgrowth,

Table 2 DNA damage induced in cortex and medulla of PA-treated, Clindamycin-treated, carnosine and carnitine protected groups

\begin{tabular}{|c|c|c|c|c|}
\hline \multirow[t]{2}{*}{ Groups } & & \multicolumn{3}{|c|}{ Parameters } \\
\hline & & Tail length $(\mu \mathrm{m})$ & Tail DNA \% & Tail moment \\
\hline \multirow[t]{2}{*}{ Control } & Cortex & $0.97 \pm 0.24$ & $0.96 \pm 0.33$ & $0.98 \pm 0.59$ \\
\hline & Medulla & $1.12 \pm 0.24$ & $1.03 \pm 0.32$ & $1.21 \pm 0.57$ \\
\hline \multirow[t]{2}{*}{ Propionic acid } & Cortex & $6.80 \pm 0.74^{* *}$ & $6.10 \pm 0.20^{* *}$ & $41.51 \pm 5.09^{* *}$ \\
\hline & Medulla & $7.27 \pm 1.33^{* *}$ & $6.67 \pm 0.99^{* *}$ & $49.32 \pm 15.53^{* *}$ \\
\hline \multirow[t]{2}{*}{ Clindamycin } & Cortex & $1.81 \pm 0.32^{*}$ & $1.71 \pm 0.36^{*}$ & $3.16 \pm 1.26^{*}$ \\
\hline & Medulla & $1.75 \pm 0.29^{*}$ & $1.64 \pm 0.40$ & $2.95 \pm 1.25$ \\
\hline \multirow[t]{2}{*}{ Carnosine } & Cortex & $1.10 \pm 0.14$ & $1.05 \pm 0.20$ & $1.18 \pm 0.36$ \\
\hline & Medulla & $1.15 \pm 0.15$ & $1.00 \pm 0.10$ & $1.16 \pm 0.27$ \\
\hline \multirow[t]{2}{*}{ Carnitine } & Cortex & $1.25 \pm 0.07$ & $1.13 \pm 0.09$ & $1.42 \pm 0.19$ \\
\hline & Medulla & $1.28 \pm 0.03$ & $1.07 \pm 0.14$ & $1.37 \pm 0.17$ \\
\hline \multirow[t]{2}{*}{ PA + Carnosine } & Cortex & $3.96 \pm 0.09^{* *}$ & $3.87 \pm 0.45^{* *}$ & $15.34 \pm 2.11^{* *}$ \\
\hline & Medulla & $3.83 \pm 0.27^{* *}$ & $3.69 \pm 0.32^{* *}$ & $14.19 \pm 2.24^{* *}$ \\
\hline \multirow[t]{2}{*}{ PA +Carnitine } & Cortex & $3.50 \pm 0.60^{* *}$ & $3.37 \pm 0.47^{* *}$ & $11.96 \pm 3.80^{*}$ \\
\hline & Medulla & $2.85 \pm 0.27^{* *}$ & $2.63 \pm 0.28^{* *}$ & $7.56 \pm 1.46^{* *}$ \\
\hline \multirow[t]{2}{*}{ clindamycin +Carnosine } & Cortex & $1.58 \pm 0.10^{*}$ & $1.42 \pm 0.09$ & $2.25 \pm 0.29^{*}$ \\
\hline & Medulla & $1.68 \pm 0.07^{*}$ & $1.23 \pm 0.12$ & $2.07 \pm 0.12$ \\
\hline \multirow[t]{2}{*}{ clindamycin+Carnitine } & Cortex & $1.73 \pm 0.20^{*}$ & $1.54 \pm 0.11^{*}$ & $2.67 \pm 0.50^{*}$ \\
\hline & Medulla & $1.70 \pm 0.21^{*}$ & $1.52 \pm 0.06$ & $2.60 \pm 0.39^{*}$ \\
\hline
\end{tabular}

Independent $t$-test between the control and PPA groups of Cortex and Medulla in Tailed \%, Untailed \%, Tail length ( $\mu$ m), Tail DNA \% and Tail moment.

* Significant at 0.05 level.

** Significant at 0.01 level 


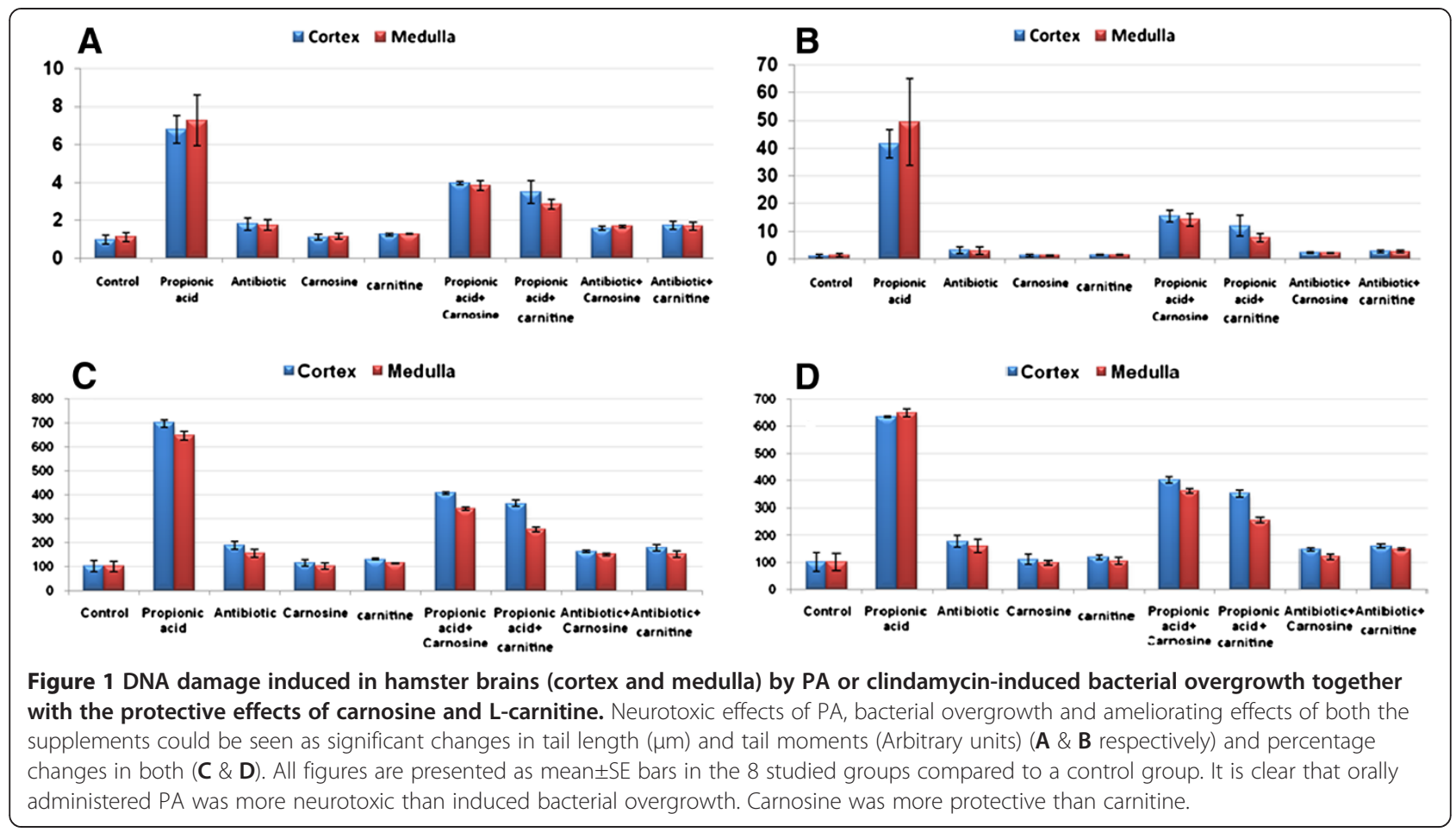

possibly due to excessive use of oral antibiotics (e.g. clindamycin), which can alter gut flora [24-27]. Oral antibiotics are commonly used by autistics for treating otitis media (ear infections), which occurs frequently in these patients. This observation may suggest an impaired immune system, a biochemical feature related to PA induced brain toxicity in rats [23]. Commonly used oral antibiotics eliminate almost all of the normal gut microbiota, which play an important role in the breakdown of plant polysaccharides, promoting gastrointestinal motility, maintaining water balance, producing some vitamins, and competing against pathogenic bacteria. Thus loss of normal gut flora with clindamycin could result in the overgrowth of pathogenic flora identified in Table 1 . This observation is supported by Buffie et al's [28] study that found a single dose of clindamycin results in the reduction of the normal diversity of the intestinal microbiota for at least 28 days and induces sustained susceptibility to $C$. difficile toxins such as propionic acid.

Table 2, Figure 1A-D and Figure 2A \& B demonstrate PA and clindamycin induced DNA damage in the cortex and medulla of treated hamsters. The evidence for DNA damage is the significant increase in the comet parameters, presented as tail length $(\mu \mathrm{m})$ in figures $A$ and $B$, tail DNA(\%) and tail moment (arbitrary units). It is clear that DNA damage produced by bacterial overgrowth induced by clindamycin-treatment was not comparable to that produced by orally administered PA in the hamsters. For example, PA induced approximately a $700 \%$ increase in tail length and tail moment, whereas, bacterial overgrowth induced a $180 \%$ increase in both the parameters. Our results indicate that the measurement of the percentages of tail DNA gives additional information on the extent of DNA damage in the cortex and medulla of PA-treated hamsters. Thus, high levels of DNA double strand breaks showed increased comet tail fluorescent intensity with ethidium bromide staining. This could prove that PA not only penetrates the blood-brain barrier, but it can also induce DNA damage in brain cells. The primary mechanism of PA-induced DNA damage is not fully understood. We postulate that PA, similar to its derivative 3nitropropionic acid (3 N-PA), could inhibit complex II of the respiratory chain leading to a rapid decline in ATP levels followed by mitochondrial DNA damage and dysfunction. ATP depletion, and mitochondrial dysfunctions are two mechanisms involved in the pathophysiology of autism [29], the postulated mechanism of PA toxicity, could confirm the role of the persisting effect of PA in the aetiology of biochemical features associated to autism as reported by El-Ansary et al. [23] in PA-treated rat pups. DNA strand breaks in the cortex and medulla of clindamycin-treated hamsters could be indirectly caused by PA as a metabolite of the induced pathogenic bacteria and due to the increased susceptibility of treated hamsters to C. difficile [28]. The remarkably higher effect of orally administered PA is likely related to the significant difference in the toxic dose administered.

Thus, clindamycin induced DNA damage could be attributed to the overgrowth of anaerobic bacteria, e.g. Clostridium that has recently been implicated as a 

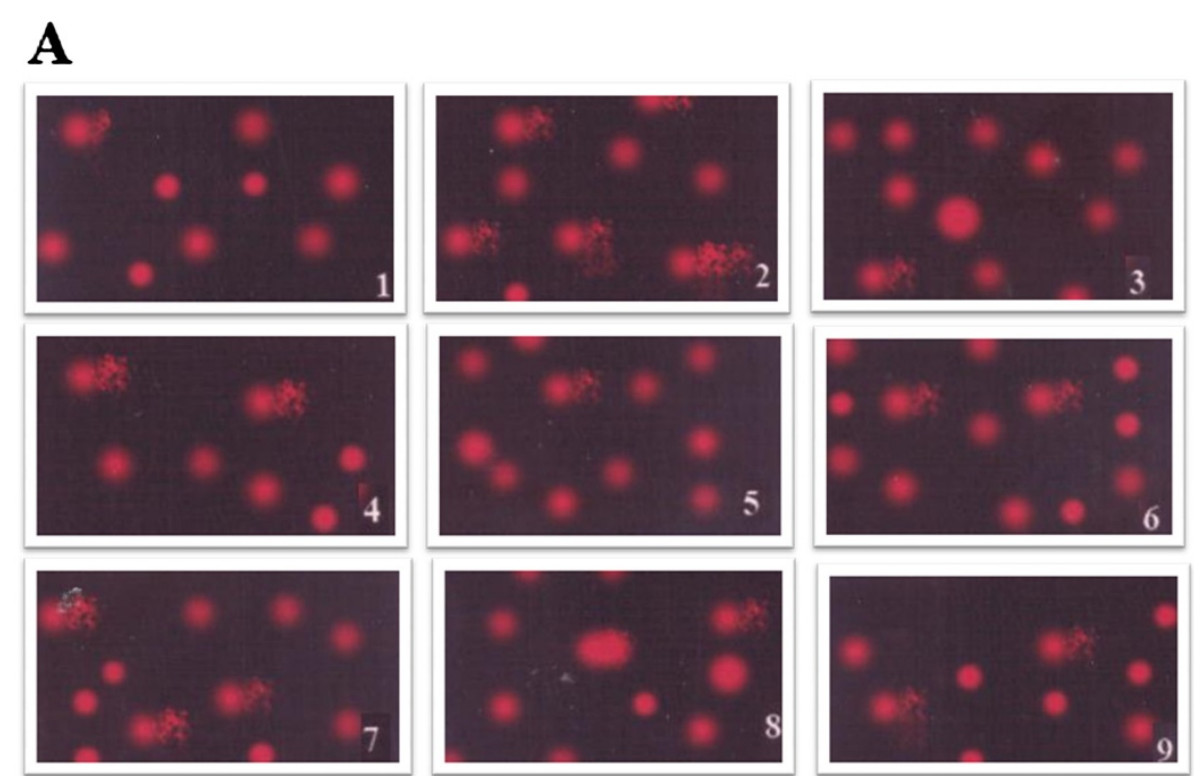

\section{B}
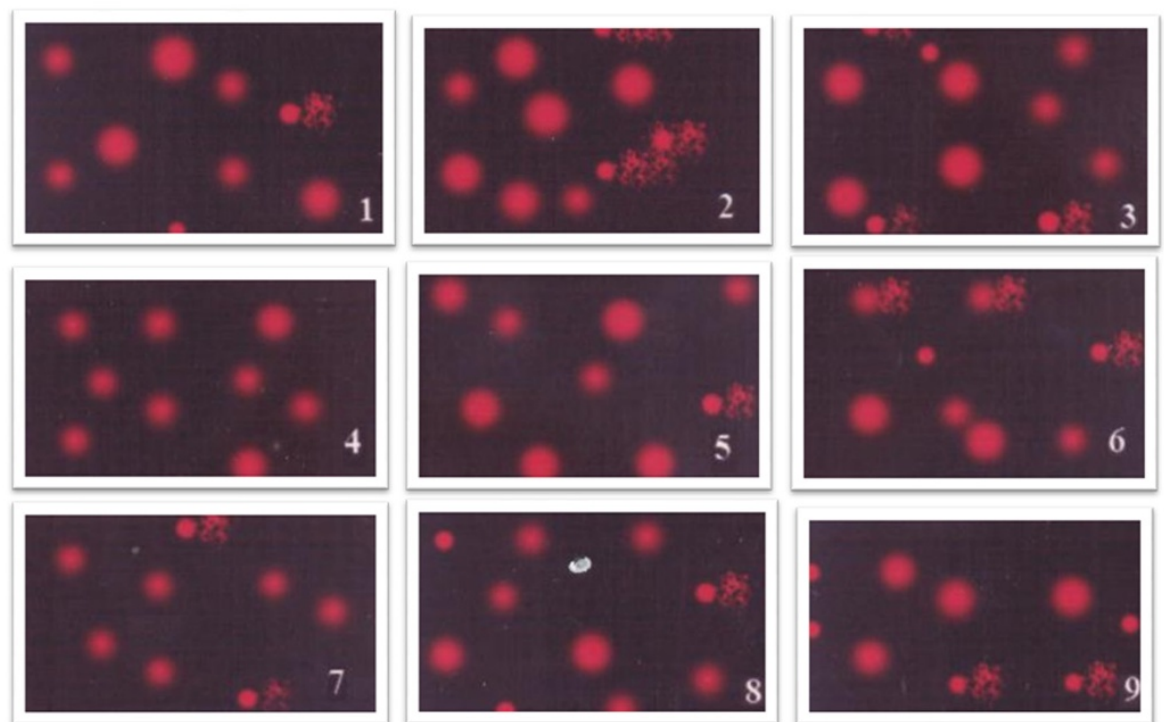

Figure 2 Measure of PA or clindamycin-induced DNA damage by comet assay. (A) Photograph showing comet tailing in PA and clindamycine treated hamsters together with the protective effects of carnosine and carnitine in cortex; (B) Photograph showing comet tailing in PA and clindamycine treated hamsters together with the protective effects of carnosine and carnitine in medulla.

causative factor involved in the etiology of autism [14]. This observation is supported by stool studies, which proved that certain Clostridia were important and that siblings of autistic children show intermediate Clostridia growth between healthy controls and their affected siblings $[8,30]$.

It has been proposed that oxidative stress is related to a time-dependent shift in the antioxidant/prooxidant balance towards oxidative damage. Increased production of oxidants in vivo can cause damage to intracellular macromolecules such as DNA, proteins and lipids, which can in turn lead to oxidative injury. Additionally, the increased nuclear DNA damage in PA and clindamycin treated animals could be related to oxidative stress status in both groups of hamsters compared to the healthy control group. Oxidative damage by a reactive oxygen species (ROS) producing toxicity can affect DNA integrity to a different extent [31,32]. This is consistent with a recent study by El-Ansary et al. [23], which reported increased lipid peroxides as an index of oxidative stress, coupled with depletion of reduced glutathione and lower catalase and glutathione peroxidase activities in PA-treated rat pups. 
Table 3 ROC-curve results for tail moment of brain cortex and medulla of the different studied groups showing AUC, best cut-off values, specificity and sensitivity

\begin{tabular}{|c|c|c|c|c|c|}
\hline Parameter & Group & Area under the curve & Best cutoff value & Sensitivity \% & Specificity \% \\
\hline \multirow[t]{8}{*}{ Cortex } & Propionic acid & 1.000 & 19.465 & $100.0 \%$ & $100.0 \%$ \\
\hline & Clindamycin & 1.000 & 1.968 & $100.0 \%$ & $100.0 \%$ \\
\hline & Carnosine & 0.667 & 0.720 & $100.0 \%$ & $66.7 \%$ \\
\hline & Carnitine & 0.667 & 0.950 & $100.0 \%$ & $66.7 \%$ \\
\hline & Propionic acid+Carnosine & 1.000 & 7.640 & $100.0 \%$ & $100.0 \%$ \\
\hline & Propionic acid+Carnitine & 1.000 & 5.642 & $100.0 \%$ & $100.0 \%$ \\
\hline & Clindamycin +Carnosine & 1.000 & 1.822 & $100.0 \%$ & $100.0 \%$ \\
\hline & Clindamycin +Carnitine & 1.000 & 1.931 & $100.0 \%$ & $100.0 \%$ \\
\hline \multirow[t]{8}{*}{ Medulla } & Propionic acid & 1.000 & 17.147 & $100.0 \%$ & $100.0 \%$ \\
\hline & Clindamycin & 1.000 & 1.910 & $100.0 \%$ & $100.0 \%$ \\
\hline & Carnosine & 0.556 & 1.209 & $66.7 \%$ & $66.7 \%$ \\
\hline & Carnitine & 0.444 & 0.882 & $100.0 \%$ & $33.3 \%$ \\
\hline & Propionic acid+Carnosine & 1.000 & 6.954 & $100.0 \%$ & $100.0 \%$ \\
\hline & Propionic acid+Carnitine & 1.000 & 3.905 & $100.0 \%$ & $100.0 \%$ \\
\hline & Clindamycin +Carnosine & 1.000 & 1.794 & $100.0 \%$ & $100.0 \%$ \\
\hline & Clindamycin +Carnitine & 1.000 & 1.963 & $100.0 \%$ & $100.0 \%$ \\
\hline
\end{tabular}

Carnitine is a vitamin-like compound that serves as a carrier to transport long-chain fatty acids (e.g. propionic acid) into the mitochondria for beta-oxidation. In the present study, the effect of L-carnitine, a widely recognized essential nutrient, was evaluated on the status of DNA damage induced in hamsters. Table 2 also demonstrates the potency of L-carnitine in protecting against PA neurotoxicity. It ameliorates the DNA damaging effects of both treatments especially in PA-treated hamsters which had a $400 \%$ recovery for the cortex and $280 \%$ recovery for the medulla. This finding supports a recent study by Ribas et al. [33] who reported that propionic acidemia leads to severe metabolic complications in the neonatal period and to long-term neurological manifestations. They [33] evaluated the in vitro effects of PA with or without L-carnitine, on DNA damage in peripheral leukocytes, as determined by alkaline comet assay. PA induced DNA damage index (DI) was significantly higher than the control group [33]. L-carnitine significantly reduced the PA induced DNA damage, in a concentration-dependent manner [33]. Administration of L-carnitine significantly decreased the levels of lipid peroxides and improved the activities of antioxidant enzymes such as superoxide dismutase, catalase, glutathione peroxidase and glutathione reductase [34]. This group of antioxidant enzymes are affected by PA neurotoxicity and are clinically impaired in autistic patients compared to controls [23]. Additionally, a protective effect of carnitine reported in the present study is likely due to L-carnitine enhanced T-cell proliferative response and significantly reduced DNA damage, apoptosis and TNF-alpha levels in the lymphocytes of aged animals [34] and in the brain of PA-intoxicated rat pups (unpublished work).

Table 2 demonstrates the effect of carnosine in inducing $300 \%$ and $350 \%$ recovery for PA-intoxicated cortex and medulla respectively. The remarkable protective effect of carnosine reported in the present study concurs with reports. Carnosine performs critical biological functions,

Table 4 Pearson correlations coefficients and significance levels between DNA \%, tail length and tail moment in cortex and medulla

\begin{tabular}{lllll}
\hline Parameters & & R (Person correlation) & Sig. & \\
\hline Cortex & Tail length Tail DNA \% & 0.990 & 0.001 & $P^{a}$ \\
& Tail length Tail moment & 0.981 & 0.001 & $P^{a}$ \\
Medulla & Tail moment Tail DNA \% & 0.965 & 0.001 & 0.001 \\
& Tail length Tail DNA \% & 0.994 & 0.001 & $P^{a}$ \\
& Tail length Tail moment & 0.977 & 0.001 & $P^{a}$ \\
& Tail moment Tail DNA \% & 0.965 & $P^{a}$ \\
\hline
\end{tabular}

\footnotetext{
a Positive Correlation.
} 

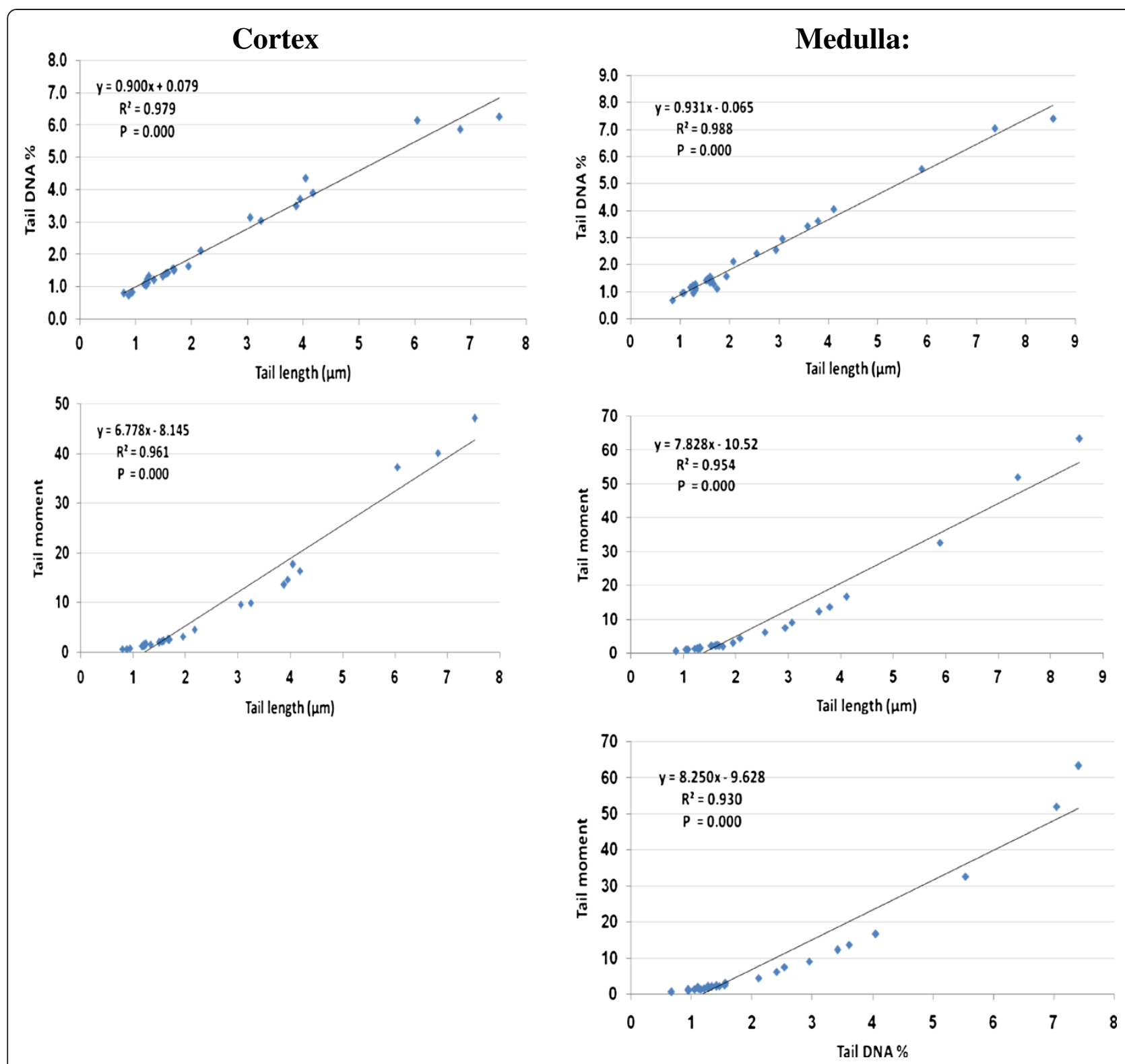

Figure 3 Pearson's positive correlations with the best fit line of the three Comet assay parameters.

in particular, antioxidant properties directed at the suppression of free radical reactions $[35,36]$. It is well known that the imidazolium group of histidine or carnosine stabilizes adducts formed at the primary amino group and may perform a crucial function as an anti-crosslinking agent [37]. The results of many biochemical studies have suggested that carnosine harbours free radical-scavenging activity, which may partly explain its apparent homeostatic functions [38,39]. Recently, in vitro and in vivo studies have shown that carnosine can exert neuroprotective effects via a variety of mechanisms [40]. It has been reported that carnosine quenches $50-95 \%$ of the hydroxyl radicals generated in the Fenton reaction [41]. Therefore, it was suggested that the ability of carnosine to inhibit ferritin-mediated DNA damage was likely attributable to free radical-scavenging activity. In a more recent study, carnosine was reported to protect neurons from lipid peroxide-induced cell injury [42].

The low or non-significant effects of both carnitine and carnosine in case of clindamycin-treated samples could be attributed to the metabolic activity of the induced growth of bacteria. Bacterial metabolic activity expressed as the fermentation profile, or short-chain fatty acid profiles, may reduce the sensitivity of colonocytes to both agents $[43,44]$.

Table 3 shows the specificity, sensitivity of tail length and tail moment in the 8 groups studied. It is clear that the specificity and sensitivity for the parameters studied were almost $100 \%$ in PA or clindamycin-treated groups 
and carnosine or carnitine-protected groups. Therefore the tail length and tail moment can be used as biomarkers for PA-related neurotoxicity and for the carnosine and/or carnitine neuroprotective effects. The three measured parameters positively correlated with statistically significant $P$ values $(P<0.001$, all parameters) (Table $4 \&$ Figure 3$)$.

Based on this study, we can suggest that the general abuse of antibiotics leads to overgrowth of Clostridia species as PA producers. The more pronounced effects of orally administered PA compared to clindamycin-treated hamsters observed in the present study could be attributed to the effect of diet which undoubtedly plays a major role in PA production as a bacterial metabolite [45].

Stated differently, key factors in the virulence of bacterial overgrowth and its mechanism leading to autism are the production of PA as an enteric bacterial fermentation product that is usually increased in the presence of a high carbohydrate diet [46]. Based on this study, a diet excluding complex carbohydrates or diets high in anti-oxidants (e.g. carnitine and/or carnosine) may subjectively give positive results in controlling the increasing prevalence of autism. This conclusion is admittedly tough to prove mechanistically and requires further study emphasizing the role of the gut-brain axis in the pathoetiology of autism [47].

\section{Competing interests}

The authors declare that they have no competing interests.

\section{Authors' contributions}

AE-A: Design the work and drafted the manuscript. GS: Performed the microbiology part. AE-G: Suggested the statistical analysis used. LA-A: codrafted the manuscript. All authors read and approved the final manuscript.

\section{Acknowledgment}

This research project was supported by a grant from the research centre for female scientific and medical colleges in King Saud University.

\section{Author details}

${ }^{1}$ Department of Biochemistry, College of Science, King Saud University, P.O Box 22452, Riyadh 11495, Saudi Arabia. ²Department of Physiology, Faculty of Medicine, King Saud University, P.O Box 22452, Riyadh 11495, Saudi Arabia. ${ }^{3}$ Autism Research and Treatment Center, Riyadh, Saudi Arabia. ${ }^{4}$ Shaik AL-Amodi Autism Research Chair, King Saud University, Riyadh, Saudi Arabia. ${ }^{5}$ Department of Microbiology and immunology, College of Pharmacy,

Zagazig University, Zagazig, Egypt.

Received: 31 March 2013 Accepted: 9 April 2013

Published: 12 April 2013

\section{References}

1. Autism and Developmental Disabilities Monitoring Network Surveillance Year 2008 Principal Investigators: Prevalence of autism spectrum disorders autism and developmental disabilities monitoring network, 14 sites, united states, 2008. MMWR Surveill Summ 2012,61:1-19.

2. Cody $\mathrm{H}$, Pelphrey $\mathrm{K}$, Piven J: Structural and functional magnetic resonance imaging of autism. Int J Dev Neurosci 2002, 20:421-438.

3. Courchesne $E$, Pierce $K$ : Brain overgrowth in autism during a critical time in development: implications for frontal pyramidal neuron and interneuron development and connectivity. Int J Dev Neurosci 2005, 23:153-170.

4. Bauman ML, Kemper TL: Neuroanatomic observations of the brain in autism: a review and future directions. Int J Dev Neurosci 2005, 23:183-187.
5. Connolly AM, Chez M, Streif EM, Keeling RM, Golumbek PT, Kwon JM, et al: Brain-derived Neurotrophic factor and autoantibodies to neural antigens in sera of children with autistic spectrum disorders, landau-kleffner syndrome, and epilepsy. Biol Psychiatry 2005, 59:354-363.

6. Araghi-Niknam M, Fatemi SH: Levels of Bcl-2 and P53 are altered in superior frontal and cerebella cortices of autistic subjects. Cell Mol Neurobiol 2003, 23:945-952.

7. Palomo T, Beninger RJ, Kostrzewa RM, Archer T: Brain sites of movement disorder: genetic and environmental agents in neuro developmental perturbations. Neurotox Res 2003, 5:1-26.

8. Finegold SM, Dowd SE, Gontcharova V, Liu C, Henley KE, Wolcott RD, et al: Pyrosequencing study of fecal microflora of autistic and control children. Anaerobe 2010, 16:444-453.

9. Finegold SM: Therapy and epidemiology of autism-clostridial spores as key elements. Medical Hypotheses 2008, 70(3):508-511.

10. MacFabe DF, Cain DP, Rodriguez-Capote K, Franklin AE, Hoffman JE, Boon F, et al: Neurobiological effects of intraventricular propionic acid in rats: possible role of short chain fatty acids on the pathogenesis and characteristics o autism spectrum disorders. Behav Brain Res 2007, 176(1):149-169.

11. Shultz SR, MacFabe DF, Ossenkopp KP, Scratch S, Whelan J, Taylor R, Cain DP: Intra cerebroventricular injection of propionic acid, an enteric bacterial metabolic end product, impairs social behavior in the rat: implications for an animal model of autism. Neuropharmacology 2008, 54(6):901-911.

12. Elsden SR, Hilton MG: Volatile acid production from threonine, valine, leucine and isoleucine by clostridia. Arch Microbiol 1978, 117(2):165-172.

13. Michelle M, Susan S, Stuart J, Dale N: Susceptibility of hamsters to human pathogenic clostridium difficile strainB1 following clindamycin, ampicillin or Ceftriaxone administration. Anaerobe 2003, 9(2):91-95.

14. MacFabe DF, Cain NE, Boon F, Ossenkopp KP, Cain DP: Effects of the enteric bacterial metabolic product propionic acid on object-directed behavior, social behavior, cognition, and neuroinflammation in adolescent rats: relevance to autism spectrum disorder. Behav Brain Res 2011, 217(1):47-54

15. Wyatt I, Farnworth M, Gyte AJ, Lock EA: L-2-chloropropionic acid metabolism and disposition in male rats: relevance to cerebellar injury. Arch Toxicol 1997, 71:668.

16. Singh NP, McCoy MT, Tice RR, Schneider EL: A simple technique for quantification of low levels of DNA damage in individual cells. Exp Cell Res 1988, 175:184-191.

17. Itoh K, Mitsuoka T, Sudo K, Suzuki K: Comparison of fecal flora of mice based upon different strains and different housing conditions. Zeitschrift fur Versuchstierkunde 1983, 25:135-146.

18. Mitsuoka T, Terada A, Morishita Y: Die darmflora von mensch und tier. Goldschmidt Informiert 1973, 73(2):23-41.

19. Holdeman LV, Cato EP, Moore WE: Anaerobe laboratory manual. 4th edition. Virginia Polytechnic Institute and State University: Blacksburg; 1977.

20. Ley RE, Turnbaugh PJ, Klein S, Gordon Jl: Microbial ecology: human gut microbes associated with obesity. Nature 2006, 444:1022-1023.

21. Kalliomäki M, Collado MC, Salminen S, Isolauri E: Early differences in fecal microbiota composition in children may predict overweight. Am J Clin Nutr 2008, 87:534-538.

22. Collado MC, Isolauri $E$, Laitinen $K$, Salminen S: Effect of mother's weight on infant's microbiota acquisition, composition, and activity during early infancy: a prospective follow-up study initiated in early pregnancy. Am J Clin Nutr 2010, 92:1023-1030.

23. El-Ansary A, Ben Bacha A, Kotb M: Etiology of autistic features: the persisting neurotoxic effects of propionic acid. J Neuroinflammation 2012. In press).

24. Adams JB, Holloway CE, George F, Quig D: Analyses of toxic metals and essential minerals in the hair of Arizona children with autism and their mothers. Biol Tr El Res 2006, 110:193-209.

25. Adams JB, Romdalvik J, Ramanujam VM, Legator MS: Mercury, lead, and zinc in baby teeth of children with autism vs controls. J Toxicol Environ Health 2007, 70(12):1046-51.

26. Adams JB, Romdalvik J, Levine KE, Hu L-W: Mercury in first-Cut baby hair of children with autism vs typically-developing children. Toxicological and Environmental Chemistry 2008, 90(4):739-753.

27. Niehus R, Lord C: Early medical history of children with autism spectrum disorders. J Dev Behav Pediatr 2006, 27(2):S120-S127. 
28. Buffie CG, Jarchum I, Equinda M, Lipuma L, Gobourne A, Viale A, Ubeda C, Xavier J, Pamer EG: Clindamycin results in sustained susceptibility to clostridium difficile-induced colitis. Infect Immun 2012, 80(1):62-73.

29. Al-Mosalem OA, El-Ansary A, Attas O, Al-Ayadhi L: Metabolic biomarkers related to energy metabolism in Saudi autistic children. Clin Biochem 2009, 42:949-957.

30. Parracho HM, Bingham MO, Gibson GR, McCartney AL: Differences between the gut microflora of children with autistic spectrum disorders and that of healthy children. J Med Microbiol 2005, 54:987-91.

31. Aitken JR, Gordon E, Harkiss D, Twigg JP, Milne P, Zo Irvine DS: Relative impact of oxidation stress on the functional competence and genomic integrity of human spermatozoa. Biol Reprod 1998, 59:1037-1046.

32. Donnelly ET, Mc Clure N, Lewis SEM: Cryopreservation of human semen and preparation of sperm: effects on motility parameters and DNA integrity. Fertil Steril 2000, 76:892-900.

33. Ribas GS, Manfredini V, de Marco MG, Vieira RB, Wayhs CY, Vanzin CS, Biancini GB, Wajner M, Vargas CR: Prevention by L-carnitine of DNA damage induced by propionic and L-methylmalonic acids in human peripheral leukocytes in vitro. Mutat Res 2010, 702(1):123-8.

34. Thangasamy $T$, Jeyakumar $P$, Sittadjody $S$, Joyee AG, Chinnakannu P: $\mathrm{L}$-carnitine mediates protection against DNA damage in lymphocytes of aged rats. Biogerontology 2009, 10(2):163-72.

35. Boldyrev AA, Dupin AM, Pindel EV, Severin SE: Antioxidative properties of histidine-containing dipeptides from skeletal muscles of vertebrates. Comp Biochem Physiol B 1988, 89:245-250.

36. Kohen R, Yamamoto Y, Cundy KC, Ames BN: Antioxidant activity of carnosine, homocarnosine, and anserine present in muscle and brain. Proc Natl Acad Sci USA 1988, 85:3175-3179.

37. Hipkiss AR, Michaelis J, Syrris P: Non-enzymatic glycosylation of the dipeptide I-carnosine, a potential anti-protein-cross-linking agent. FEBS Lett 1995, 371:81-85.

38. Decker EA, Livisay SA, Zhou S: A re-evaluation of the antioxidant activity of purified carnosine. Biochemistry (Moscow) 2000, 65:766-770.

39. Kang JH, Kim KS, Choi SY, Kwon HY, Won MH, Kang TC: Carnosine and related dipeptides protect human ceruloplasmin against peroxyl radical mediated modification. Mol Cells 2002, 13:498-502.

40. Rajanikant GK, Zemke D, Senut MC, Frenkel MB, Chen AF, Gupta R, Majid A Carnosine is neuroprotective against permanent focal cerebral ischemiain mice. Stroke 2007, 38:3023-3031.

41. Babizhayev MA, Seguin MC, Gueyne J, Evstigneeva RP, Ageyeva EA, Zheltukhina GA: L-carnosine (beta-alanyl-L-histidine) and carcinine (betaalanylhistamine) act as natural antioxidants with hydroxyl-radical -scavenging and lipidperoxidase activities. Biochem J 1994, 304(2):509-16.

42. Cheng J, Wang F, Yu DF, Wu PF, Chen JG: The cytotoxic mechanism of malondialdehyde and protective effect of carnosine via protein cross linking/mitochondrial dysfunction/reactive oxygen species. MAPK pathway in neurons European Journal of Pharmacology 2011, 650:184-194.

43. Klewicka E, Zdun' czyk Z, Ju'skiewicz J: Effect of lactobacillus fermented beetroot juice on composition and activity of cecal microflora of rats. Eur. Food Res. Technol 2009, 229:153-157.

44. Dias CM, Vieiralves FL, Gomes MIFV, Salvadori DMF, Rodrigues MAM, Barbisan LF: Effect of lycopene,symbiotic and their association on early biomarkers of rat colon carcinogens. Food Chem. Toxycol 2010, 48:772-780.

45. Finegold S, Downes J, Summanen P: Microbiology of regressive autism Anaerobe 2012, 18:260-262

46. Hudson MJ, Marsh PD: Carbohydrate metabolism in the colon. In Human colonic bacteria: role in nutrition, physiology, and pathology. Edited by Gibson GR, Macfarlane GT. Boca Raton, FL: CRC Press; 1995:61-73.

47. Gotschall E: Digestion-gut-autism connection: the specific carbohydrate diet. Medical Veritas 2004, 1:261-271.

doi:10.1186/1757-4749-5-9

Cite this article as: El-Ansary et al:: The neurotoxic effect of clindamycin - induced gut bacterial imbalance and orally administered propionic acid on DNA damage assessed by the comet assay: protective potency of carnosine

and carnitine. Gut Pathogens 2013 5:9.

\section{Submit your next manuscript to BioMed Central and take full advantage of:}

- Convenient online submission

- Thorough peer review

- No space constraints or color figure charges

- Immediate publication on acceptance

- Inclusion in PubMed, CAS, Scopus and Google Scholar

- Research which is freely available for redistribution

Submit your manuscript at www.biomedcentral.com/submit 